\title{
Linking Indigenous Communities with Regional Development
}

Written by: Dawn Madahbee Leach, General Manager - Waubetek Business Development Corporation, and Vice-Chair of the National Indigenous Economic Development Board of Canada, Lars-Anders Baer, Chairperson of the Working Group for Indigenous Peoples to the Barents Euro-Arctic Co-operation and Peter $\mathrm{Yu}$, Chief Executive Officer of Nyamba Buru Yawuru Ltd and Chair of the Indigenous Reference Group to the Northern Ministerial Council.

Last update: 17 August 2020

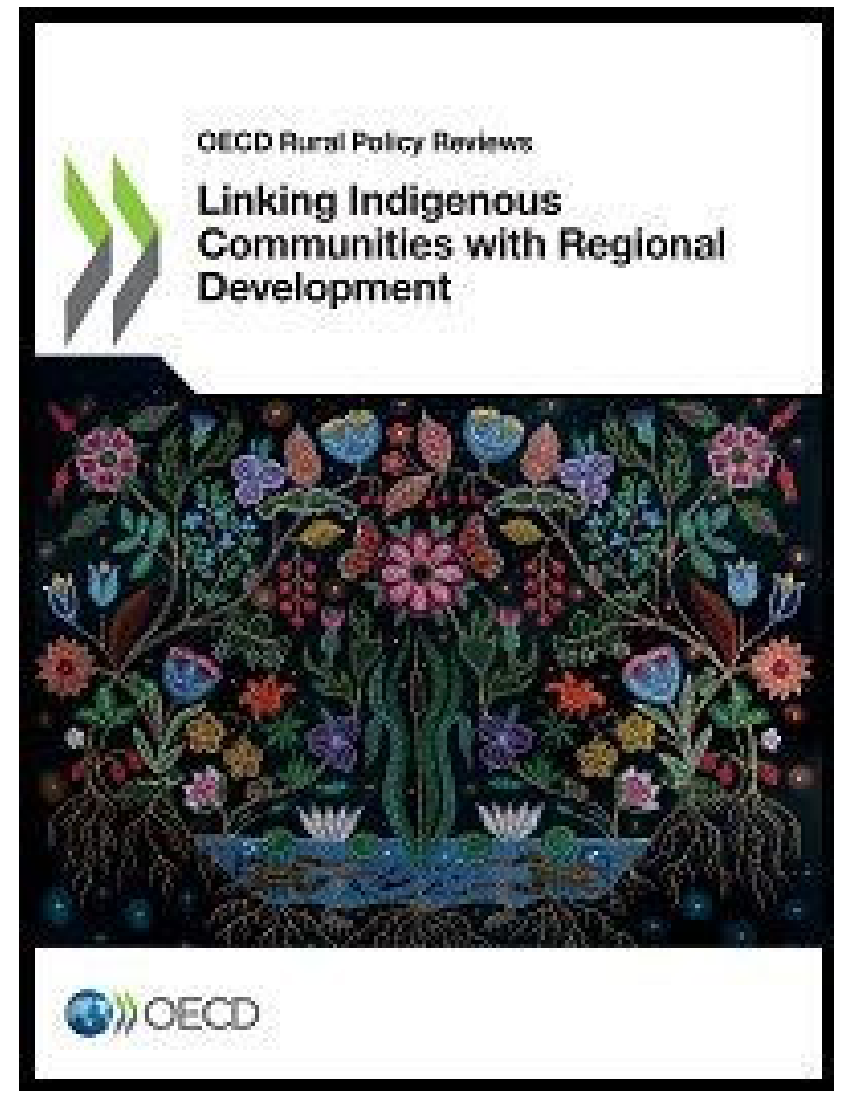

Linking Indigenous Communities with Regional Development

We are pleased to have provided leadership and guidance on this report-the first-ever global study of its kind on Indigenous economies and regional development. This work has directly 
involved Indigenous communities and leaders throughout. It is also timely. As Indigenous peoples worldwide achieve growing legal recognition of their rights as well as title to land and sea, it is imperative that we overcome the implementation gap and translate these rights into better outcomes. Reconciliation involves addressing Indigenous land title along with the meaningful engagement of the original people in planning the protection and sustainable use of lands, water, natural resources and wildlife. It also demands the inclusion of Indigenous peoples and perspectives in governance and policy design at all levels.

We are stewards of the lands and waters-a responsibility given to us by the Creator. All life relies on the gifts that Mother Earth has provided by plant life, waters, animal beings, air and the grandfather stones. We must balance our use and need of these gifts in a sustainable and environmentally responsible way. Indigenous peoples have survived on the lands and hold an innate knowledge and connection to the lands that we have occupied for millennia. This is a worldview that is critical for all peoples to understand and embrace in order to sustain the earth for generations to come. That is why it is so integral to link Indigenous peoples to regional decision making and development.

Historic injustices have prevented indigenous peoples from exercising their rights to development in accordance with their own needs and interests. Indigenous peoples have been colonised, dehumanised, subjugated and dispossessed of their lands and resources. Where treaties were entered into with indigenous governments to share the lands and resources, they have too often been breached. Fortunately in some places, reconciliation is starting to take root. The United Nations Declaration on the Rights of Indigenous Peoples and the successive International Labour Organization's conventions (no 107/1957 and no 169/1989) are being adopted and incorporated in the laws of many countries throughout the world who recognise the richness that indigenous peoples can bring to the social and economic fabric of a country. Despite the many socioeconomic challenges we face, indigenous peoples are building capacity, creating businesses, undertaking economic development, contributing to regional economies and sharing the beautiful values of our culture.

The capacity for indigenous peoples to create secure and sustainable wealth is fundamental to the universal indigenous quest for self-determination. It is therefore imperative for indigenous peoples to decide how that should proceed on the principles of free, prior and informed consent. We want to navigate our own way in a modern economy where we ensure the correct balance of our customary and cultural obligations to self, community and country while at the same time activating our natural tangible and intangible assets to grow our strength and independence. In the end, we want to resume responsibility and "own our risk". 
This report demonstrates the value of sharing lessons between indigenous peoples across countries. It shares some of our leading practices such as the fisheries initiatives of indigenous peoples in Alaska, the mining project of the Gumaj Corporation in Northern Australia, the parliament structure of the Sami in Sweden or the models of Indigenous financial institutions in Canada. We have Indigenous communities worldwide that have built their own economies through community-owned businesses, managing their own lands, training their own people and strengthening their own governance practices while incorporating their unique cultural traditions. We look forward to the future as we build on each other's successes, share our stories and cheer on our accomplishments.

This report demonstrates that Indigenous peoples can be full participants and equal beneficiaries in economic development. We are pleased at how this report underlines the importance of re-establishing and strengthening governance structures that empower indigenous communities. From regional policies and programming to better statistics, it provides a roadmap to fulfil the needs and aspirations of indigenous peoples. It is also a roadmap for OECD member and nonmember countries to meet the rights and aspirations of Indigenous peoples and communities so that they can realise their vast potential.

Miigwetch, Giitu, and Gala Mabu to the OECD for embarking on this path with us! Dawn Madahbee Leach

General Manager, Waubetek Business Development Corporation, and Vice-Chair of the National Indigenous Economic Development Board of Canada

Lars-Anders Baer

Chairperson of the Working Group for Indigenous Peoples to the Barents EuroArctic Co-operation

Peter Yu

Chief Executive Officer of Nyamba Buru Yawuru Ltd and Chair of the Indigenous Reference Group to the Northern Ministerial Council.

All signed articles in the OECD Observer express the opinions of the authors and do not necessarily represent the official views of the OECD or its member countries.

@OEED Observer August 2019

\section{References}

OECD (2019), Linking Indigenous Communities with Regional Development, OECD Rural Policy Reviews, OECD Publishing, Paris http://dx.doi.org/https:// doi.org/10.1787/3203c082-en 